\title{
Placenta Growth Factor and Soluble Fms-Like Tyrosine Kinase 1 in Preeclampsia and Normotensive Pregnant Nigerian Women
}

\author{
Abidoye Gbadegesin*, Joy O. Agbara, Kabiru A. Rabiu, Adekunle A. Sobande, \\ Madinah A. Azeez \\ Department of Obstetrics and Gynaecology, Lagos State University Teaching Hospital, Ikeja, Lagos, Nigeria \\ Email: *abidoye.gbadegesin@lasucom.edu.ng
}

How to cite this paper: Gbadegesin, A., Agbara, J.O., Rabiu, K.A., Sobande, A.A. and Azeez, M.A. (2021) Placenta Growth Factor and Soluble Fms-Like Tyrosine Kinase 1 in Preeclampsia and Normotensive Pregnant Nigerian Women. Open Journal of Obstetrics and Gynecology, 11, 753-762. https://doi.org/10.4236/ojog.2021.116070

Received: May 11, 2021

Accepted: June 15, 2021

Published: June 18, 2021

Copyright $\odot 2021$ by author(s) and Scientific Research Publishing Inc. This work is licensed under the Creative Commons Attribution International License (CC BY 4.0).

http://creativecommons.org/licenses/by/4.0/

(c) (i) Open Access

\begin{abstract}
Background: Preeclampsia (PE) is still one of the leading causes of maternal/perinatal morbidity/mortality in Nigeria. Imbalance between placenta growth factor (PLGF) and soluble fms-like tyrosine kinase 1 (sFlt1) has been reportedly present both before and after the manifestation of PE; however, Nigerian data regarding these angiogenesis-related substances are lacking. We here attempted to determine the maternal serum level of PLGF and sFlt1 and sFlt1/PLGF ratio in PE vs. non-PE women in Lagos State University Teaching Hospital, Nigeria. Methods: An observational cross-sectional study was made on 75 women with PE and 75 age-gestational-age matched women without PE, as case and control, respectively. Levels of sFlt-1, PIGF and the sFlt-1: PIGF ratio was compared between the two. Results: Serum levels of Flt-1 and sFlt1/PIGF ratio were significantly higher in PE patients (6581.86 \pm 865.75 , and $146.42 \pm 92.43)$ than in the normotensive control (4584.52 \pm 1479.6 and $11.60 \pm 6.42)$. PIGF was significantly lower in PE patients $(70.14 \pm$ $51.03)$ than the normotensives $(494.06 \pm 475.8)$. There were positive and negative correlations between the sFlt-1 and PLGF respectively and mean arterial blood pressure. Conclusion: Serum sFlt-1, sFlt1/PIGF ratio was significantly higher and PIGF levels were significantly lower in PE than normotensive control in Nigerian population.
\end{abstract}

\section{Keywords}

Preeclampsia, Soluble Fms-Like Tyrosine Kinase 1 (sFlt-1), Placental Growth Factor (PlGF), Pregnancy 


\section{Background}

Pre-eclampsia is a multifactorial hypertensive disorder whose pathogenesis is not fully understood. Defective remodeling of the spiral arteries causing hypoperfusion and systemic dysfunction and a subsequent imbalance of circulating proangiogenic and antiangiogenic factors are considered to be one of the possible aetiology for this disorder [1] [2] [3]. Normal placental angiogenesis is crucial to the development of effective placental perfusion, creating a suitable uterine environment, and ensuring the normal growth of the fetus. Pro-angiogenic factors play a key role in this process [4]. It is currently believed that the imbalance of pro-angiogenic factors and anti-angiogenic factors is one of the pathogenesis of PE, as it can affect the remodeling of uterine spiral arteries and angiogenesis [5]. The proangiogenic proteins vascular endothelial growth factor (VEGF) and placental growth factor (PIGF) are involved in the regulation of placental vascular development and maternal endothelial function during pregnancy [6] [7].

The soluble variant of VEGF receptor-1 is also known as soluble fms-like tyrosine kinase-1 (sFlt-1) [8]. sFlt1 has become a relevant pathogenic factor for the syndrome PE. Studies have reported an elevation of maternal sFlt1 concentrations in PE which is observed to normalize after delivery [9] [10]. Notably, clinical studies demonstrated that the marked increase of circulatory sFlt1 is observable weeks before the clinical manifestation of preeclampsia [11] [12]. It is also reported that the increased serum levels of sFlt-1, decreased levels of PIGF and resultant increased sFlt-1/PIGF ratio, can be detected in the second half of pregnancy in women diagnosed with pre-eclampsia and in other placenta-related disorders like intra-uterine growth restriction (IUGR) or stillbirth [9]. These alterations are observed to be pronounced in early-onset rather than lateonset disease and are associated with severity of the clinical disorder. Moreover, the disturbances in angiogenic factors are reported to be detectable prior to the onset of clinical symptoms (disease), thereby allowing discrimination of women with normal pregnancies from those at high risk for preeclampsia. Increasing evidences showed that the degree of elevated or declined level of these analytes was correlated with the severity of preeclampsia. A diagnosis of PE based on blood pressure and proteinuria has a positive predictive value of approximately $30 \%$ for predicting PE related adverse outcomes [13]. Therefore, estimation of maternal sFlt-1 and PlGF seems to be the most promising serological indicators for diagnosis, especially the sFlt-1/PlGF ratio, which better reflects the antiangiogenic activity and could be used to predict the occurrence and prognosis of preeclampsia. [9] [10] [11] allow identification of affected women at high risk for imminent delivery and prevention of adverse maternal and neonatal outcomes. [14] [15] [16] Combining the sFlt-1/PlGF ratio with uterine artery Doppler ultrasound at the time of diagnosis of early-onset pre-eclampsia is documented to be of prognostic value mainly for perinatal complications, though limited for the prediction of maternal complications [17]. The additional measurement of 
the sFlt-1/PlGF ratio has been shown to improve the sensitivity and specificity of Doppler measurement in predicting PE [18].

Of recent, the focus of research is being directed at the role of biochemical markers in the pathogenesis of $\mathrm{PE}$ for better understanding of the disease process. One of such markers is the alterations in maternal serum concentrations of anti-angiogenic (sFlt-1) and pro-angiogenic factors (VEGF and PlGF) [11]. Interestingly, the sFlt-1/PlGF ratio has been demonstrated to show better performance than single markers in predicting the risk of PE [19] [20]. The alteration of the balance between concentration of pro-angiogenic factors, VEGF and PIGF, and anti-angiogenic factors like sFlt- 1 and Endoglin has been documented in the pathophysiology of preeclampsia [21]. The potential relevance of this imbalance and especially the sFlt-1/PIGF ratio in the diagnosis and prognosis of this disease entity has remained an area of interest with the hope to improve management and feto-maternal outcomes.

This study aims to assess the levels and association between angiogenic and anti angiogenic factors in $\mathrm{PE}$ and normotensive pregnant women receiving care in a tertiary health centre in Nigeria. Ethical approval for the study was obtained from the Research and Ethics Committee of the institution.

\section{Materials and Method}

This observational cross-sectional study was carried out in the Department of Obstetrics and Gynaecology of the Lagos State University Teaching Hospital, Ikeja, Lagos State from $1^{\text {st }}$ August 2016 to $28^{\text {th }}$ February, 2017. Pregnant women with viable singleton fetus in their third trimesters (28weeks of gestation till delivery), diagnosed with pre-eclampsia and matched for age, parity, and gestational age at recruitment with those who are healthy and normotensive were recruited by purposive sampling from the antenatal clinics, lying in wards and the emergency unit as cases and control respectively.

Women with gestational diabetes, infectious disease, premature rupture of membranes, preterm or term labour, multiple fetuses, renal disease, chronic hypertension, other medical conditions and who did not give informed written consent were excluded.

The sample size was calculated using Leslie Fisher's formula [22], $N=(Z \alpha+Z \beta)^{2}\left(P_{o}\left(1-P_{0}\right)+P_{1}\left(1-P_{1}\right)^{2}\right) /\left(P_{1}-P_{0}\right)^{2}$. Where $N=$ required minimum sample size in each group; $Z \alpha=\%$ of normal distribution corresponding to the required significant level of $5 \%=1.96 ; Z \beta=$ point of normal distribution corresponding to the statistical power of $80 \%=0.842 ; P_{o}=$ response in the first group got from previous study $=0.90 ; P_{1}=$ expected response in the second group $=0.80$. Approximately 50 was calculated in each group, but was increased to 75 to control for attrition. All the women were followed up till delivery. The blood pressure of the control group was monitored to ensure they remained normotensive for the duration of pregnancy otherwise were excluded. Medical case files were reviewed and demographic data including obstetric history, med- 
ical and family history, examination findings at diagnosis and feto-maternal outcome of pregnancy were collected.

PE was diagnosed using the criteria from the International Society for the Study of Hypertension in Pregnancy (ISSHP). [23]. Hypertension was defined as blood pressure of $\geq 140 / 90 \mathrm{mmHg}$ on 2 or more consecutive occasions $\geq 4$ hours apart or as a diastolic blood pressure of $\geq 110 \mathrm{mmHg}$ on any one occasion. Proteinuria was defined as a clean catch midstream or catheter urine specimen with $\geq 2+$ proteinuria on reagent strip. Severe PE was defined by blood pressure of $\geq 160 / 110 \mathrm{mmHg}$ with $\geq 2+$ proteinuria or any degree of hypertension with complications such as eclampsia, HELLP syndrome and any other end organ damage. The blood pressure at the brachial artery was measured using a mercury sphygmomanometer on two occasion, 4 - 6 hours apart after adequate rest. Mean arterial blood pressure was calculated as Diastolic blood pressure $+1 / 3$ Pulse pressure (Pulse pressure $=$ Systolic blood pressure - Diastolic blood pressure). Gestational ages were calculated using the last menstrual period (LMP) and/or first trimester or early mid trimester ultra-sonographic scan.

Blood samples were drawn at recruitment for each participant. Five (5 mls) of venous blood was collected from the patients into plain bottles that was well labelled for proper identification and left for 2 hours to clot and retract and then centrifuged at 2500 RPM for 5 minutes. The serum was decanted into vials and stored at $-80^{\circ} \mathrm{C}$ until analysis. Maternal serum sFlt- 1 and PIGF were assayed using the Abcam PLC, Cambridge, United Kingdom Enzyme Linked Immunosorbent Assay (ELISA) Diagnostic kits according to manufacturer's instruction.

The women with PE (cases) were sub-divided into mild and severe PE groups. The sflt1/PIGF ratio was calculated for each participant and a cut off value of 85 for the sFlt-1/PIGF ratio was used. The values of the ratio of analytes were regrouped into high if $>85$ and low if $<$ than 85 . Patients who had at least one fetal complication was categorized to have adverse fetal outcome, likewise, patients who had at least one maternal complication was categorized to have adverse maternal outcome.

Data were analysed using the Epi info 3.5.3 statistical software (2011) of the Centre for disease control, Atlanta Georgia, USA and Statistical Package for Social Sciences (SPSS) (version 20.0, SPSS Inc., Chicago, Illinois, USA). Percentage, means and standard deviation of numerical variables were determined. Independent $\mathrm{t}$-test and analysis of variance was used to compare numeric variables. Chi Square test was used to compare categorical variables. Correlation was determined using the Pearson's correlation co-efficient. Odds ratio and confidence interval were determined using logistic regression. P-value less than 0.05 was considered to be statistically significant. The confidence interval was set at $95 \%$ for all statistical test.

\section{Results}

A total of 150 patients ( 75 patients in the pre-eclampsia and 75 patients in the 
control groups) were recruited for this study. The clinical details of the patients are shown in Table 1. There was no significant difference in ages, parity and gestational ages in the women studied. Nulliparous parturient accounted for approximately half of the total population of these women. In the PE group, 15 (20\%) had mild PE while $60(80 \%)$ had severe disease. The difference in mean systolic, diastolic and mean arterial blood pressures between the groups were statistically significant $(\mathrm{p}$ value $=0.0000)$. Table 2 shows that the mean serum PIGF was significantly lower in the PE group $(70.14 \pm 51.03 \mathrm{pg} / \mathrm{ml})$ compared to the control $(494.06 \pm 475.81 \mathrm{pg} / \mathrm{ml})$ group with $\mathrm{p}$-value $=0.0000$. Maternal serum sFlt-1 was significantly higher in PE $(6581.86 \pm 865.75 \mathrm{pg} / \mathrm{ml})$ compared with normotensive $(4584.50 \pm 147.96 \mathrm{pg} / \mathrm{ml})$ pregnancies, $\mathrm{p}$ value $=0.0000$. The sFlt-1/PIGF ratio was significantly higher in those with PE (149.42 \pm 92.43$)$ than in the control $(11.60 \pm 6.42)$ group, $P$ value $=0.0000$. Further comparative analysis of the levels and ratio of the analytes between women with mild and severe PE showed that patients with severe PE had a lower mean PIGF $(51.60 \pm 38.53$ $\mathrm{pg} / \mathrm{ml}$ ) that was not statistically significant compared to those with mild PE $(74.78 \pm 52.96 \mathrm{pg} / \mathrm{ml}), \mathrm{p}$-value $=0.1162$. Also the mean sFlt-1 level was slightly higher in severe PE group $(6600.00 \pm 763.45 \mathrm{pg} / \mathrm{ml})$ compared to the mild PE group $(6577.33 \pm 895.36 \mathrm{pg} / \mathrm{ml})$ but increase was not significant, $\mathrm{p}$-value $=$ 0.9211 . There was no significant difference in the mean sFlt-1/PIGF ratio between severe PE group (186.84 \pm 96.72) and the mild PE group (140.07 \pm 89.73$)$, p-value $=0.0795$ (Table 3 ). The mean sFlt-1/PIGF ratio was significantly higher in women who had adverse fetal outcome compared to those with those who had none. There was however, no significant difference in the ratio in those who had adverse maternal outcome (Table 4).

The risk of adverse fetal outcome was observed to increase by 3.6 fold in patients with high sFlt-1/PIGF ratio compared to those with low ratio and this was

Table 1. Clinical details of patients.

\begin{tabular}{lccc}
\hline \multicolumn{1}{c}{ VARIABLES } & $\begin{array}{c}\text { PREECLAMPSIA } \\
\mathbf{N}=\mathbf{7 5}\end{array}$ & $\begin{array}{c}\text { CONTROL } \\
\mathbf{N}=\mathbf{7 5}\end{array}$ & P-VALUE \\
\hline $\begin{array}{l}\text { AGE (YEARS) } \\
\quad \text { Mean } \pm \text { SD }\end{array}$ & $29.38 \pm 4.97$ & $30.01 \pm 19.93$ & $0.4178^{*}$ \\
$\quad$ Range & $16-42$. & $16-42$. & \\
PARITY & & & \\
$\quad \mathbf{0}$ & $37(49.3 \%)$ & $27(36 \%)$ & $0.1870^{*}$ \\
$\quad$ 1 - 4 & $36(48 \%)$. & $47(62.7 \%)$ & \\
$\quad$ 5 And Above & $2(2.7 \%)$ & $1(1.3 \%)$ & \\
GESTATIONAL AGE (WEEKS) & $34.3 \pm 3.41$ & $34.11 \pm 3.26$ & 0.8073 \\
RANGE & $27-40$ & $27-40$ & \\
MEAN SYSTOLIC BP (mmHg) & $168.4 \pm 19.9$ & $111.6 \pm 9.52$ & 0.0000 \\
MEAN DIASTOLIC BP (mmHg) & $106.8 \pm 11.71$ & $66.2 \pm 6.93$ & 0.0000 \\
MABP (mmHg) & $127.3 \pm 13.17$ & $81.37 \pm 6.9$ & 0.0000 \\
\hline
\end{tabular}

* = chi square test, \# = student's $\mathrm{t}$-test. 
Table 2. Mean levels of angiogenic (PIGF), anti-angiogenic (sFlt-1) and sFlt-1/PIGF ratio among the patients studied.

\begin{tabular}{cccc}
\hline MEAN \pm SD & $\begin{array}{c}\text { PREECLAMPSIA } \\
\mathrm{N}=75\end{array}$ & $\begin{array}{c}\text { CONTROL } \\
\mathbf{N}=75\end{array}$ & P-VALUE \\
\hline PIGF $(\mathrm{pg} / \mathrm{ml})$ & $70.14 \pm 51.03$ & $494.06 \pm 47.58$ & 0.0000 \\
sFlt-1 $(\mathrm{pg} / \mathrm{ml})$ & $6581.86 \pm 865.75$ & $4584.5 \pm 1479.6$ & 0.0000 \\
sFlt-1/PIGF Ratio & $149.42 \pm 92.43$ & $11.60 \pm 6.42$ & 0.0000 \\
\hline
\end{tabular}

Table 3. Mean levels of angiogenic (PIGF), anti-angiogenic (sFlt-1), sFlt-1/PIGF ratio in patients with mild and severe preeclampsia.

\begin{tabular}{cccc}
\hline MEAN \pm SD & SEVERE PREECLAMPSIA & MILD PREECLAMPSIA & P-VALUE \\
& $\mathrm{N}=60$ & $\mathrm{~N}=15$ & \\
\hline PIGF $(\mathrm{pg} / \mathrm{ml})$ & $51.60 \pm 38.53$ & $74.78 \pm 52.96$ & 0.1162 \\
sFlt-1 $(\mathrm{pg} / \mathrm{ml})$ & $6600.00 \pm 763.45$ & $6577.333 \pm 895.36$ & 0.9211 \\
sFlt-1/PIGF Ratio & $186.84 \pm 96.72$ & $140.07 \pm 89.73$ & 0.0795 \\
\hline
\end{tabular}

Table 4. Mean levels of sFlt-1/PIGF ratio stratified with adverse fetomaternal outcome in preeclampsia group.

\begin{tabular}{lccc}
\hline \multicolumn{1}{c}{ ADVERSE OUTCOME } & YES & NO & P-VALUE \\
\hline FETAL & & & \\
Birth Asphyxia & $235.47 \pm 101.04$ & $140.57 \pm 87.57$ & 0.0088 \\
IUFD & $274.15 \pm 33.05$ & $130.24 \pm 83.19$ & 0.0000 \\
NND & $333.3 \pm 0.00$ & $146.94 \pm 90.50$ & 0.0444 \\
NICU Admission & $197.38 \pm 88.16$ & $139.37 \pm 90.79$ & 0.0388 \\
Low Birth Weight & $212.73 \pm 75.06$ & $104.80 \pm 75.86$ & 0.0000 \\
MATERNAL & & & \\
Eclampsia & $153.79 \pm 118.17$ & $148.83 \pm 89.47$ & 0.0881 \\
ICU Admission & $133.33 \pm 0.00$ & $149.64 \pm 93.28$ & 0.8122 \\
Renal Failure & $161.20 \pm 164.86$ & $149.10 \pm 91.65$ & 0.8566 \\
Maternal Death & $277.77 \pm 0.00$ & $147.69 \pm 91.83$ & 0.1636 \\
HELLP Syndrome & $133.3 \pm 0.00$ & $149.64 \pm 93.28$ & 0.5790 \\
Abruptio placentae & $133.33 \pm 0.00$ & $138.57 \pm 84.33$ & 0.4332 \\
\hline
\end{tabular}

statistically significant $(\mathrm{p}$ value $=0.0263)$. However, the presence of high sFlt-1/ PIGF ratio did not increase the risk of adverse maternal outcome (Odd Ratio 1.03, CI $0.24-4.42$, P value $=0.9608$ ) Table 5 . After correcting for early onset $\mathrm{PE}$ and other co-variate (maternal outcome) the previously significant fetal adverse outcome associated with high sFlt-1/PIGF was no longer significant (Odd Ratio 1.89 , CI $0.3-8.5, \mathrm{P}$ value $=0.450$ ). Using Pearson's correlation, the study revealed that sFlt-1 and sFlt-1/PIGF ratio had a significant and positive correlation with the mean arterial blood pressure and the PIGF had a significant but very strong negative correlation with the mean arterial blood pressure.

\section{Discussion}

Our study assessed the serum concentration of PIGF and sFlt-1 and their ratio in 
Table 5. Association of adverse foetomaternal outcome with sFlt-1/PIGF ratio.

\begin{tabular}{|c|c|c|c|c|c|c|c|c|}
\hline & & & CRUDE & & & ADJUSTED & & \\
\hline HIGH RATIO & $\begin{array}{l}\text { ADVERSE } \\
\text { OUTCOME }\end{array}$ & $\begin{array}{l}\text { NO ADVERSE } \\
\text { OUTCOME }\end{array}$ & ODD RATIO & $95 \% \mathrm{CI}$ & P-VALUE & ODD RATIO & $95 \%$ CI & P-VALUE \\
\hline \multicolumn{9}{|l|}{ FETAL } \\
\hline YES & $26(83.9 \%)$ & $26(59.1 \%)$ & 3.6 & $(1.4-11.4)$ & 0.0263 & 1.89 & $(0.3-8.5)$ & 0.45 \\
\hline NO & $5(16.1 \%)$ & $18(4.9 \%)$ & & & & & & \\
\hline \multicolumn{9}{|l|}{ MATERNAL } \\
\hline YES & $7(70.0 \%)$ & $45(69.2 \%)$ & 1.03 & $(0.24-4.42)$ & 0.9608 & 0.60 & $(0.05-6.64)$ & 0.68 \\
\hline NO & $3(30.0 \%)$ & & & & & & & \\
\hline
\end{tabular}

Crude Odds Ratio Adjusted for early onset preeclampsia and other co-variate.

pregnant women with $\mathrm{PE}$ and compared with their normotensive counterparts in the third trimester and looked into its potential as a marker of disease severity and adverse feto-maternal outcomes.

In this study, maternal serum PIGF level was significantly lower in women with PE compared to those with normotensive pregnancies. Conversely, the serum sFlt-1 and sFlt-1/PIGF ratio were significantly higher in the PE compared with the normotensives. These findings are in concordance with other studies [9] [10] [13]. The mechanisms responsible for the alteration of maternal plasma sFlt-1 and PIGF concentrations in women with PE are not fully understood. However, in-vitro studies suggest that the altered levels of these factors may occur in response to placental hypoxia following reduced oxygen tension resulting in incomplete remodeling of spiral arteries and neo-angiogenesis which are essential to placental health and growth in normal pregnancy [6].

Our result showed a non-significant increase in sFlt-1 in patients with severe PE compared to those with mild PE. This was at variance with that documented in other studies [6] [13], where a significant increase in the level of sFlt-1 in those with severe PE compared with those with mild disease was found. This difference may be due to the difference in gestational ages at recruitment and at the same time may suggest a racial variation. There was a non-significant decrease in PIGF in patients with severe PE compared to those with mild PE which differed from findings documented in other studies [6] [9]. The sFlt-1/PIGF ratio was not significantly increased in severe PE than mild PE ( $p=0.0795)$ as documented in other studies. Our finding was however, similar to that documented by Nikuei et al., who observed that although the ratio was higher in severe PE than mild PE, the difference was not statistically significant, $\mathrm{p}=0.389$ [20]. Chaiworapongsa and co-workers [14] documented that increasing sFlt-1 correlates with disease severity, this was not observed in this study.

This study showed that there was a significant high sFlt-1/PIGF ratio associated with fetal adverse outcome in PE patients compared to those without any adverse outcome as found in other studies [24] [25] [26]. On the contrary there was a non-significant increase in sFlt-1/PIGF ratio in patients with adverse ma- 
ternal outcome amongst PE patients. Most of the studies showed a high sFlt-1/ PIGF ratio to be associated with adverse outcome both in singleton and in multiple pregnancy [28]. SFlt-1/PIGF ratio has been found to outweigh other clinical and laboratory tests in predicting adverse outcome [27] [28].

It was also found that there is at least a 3 - 4 fold risk of developing fetal adverse outcome in the pre-eclampsia group. Further adjustment with other co variate was not statistically significant with fetal adverse outcome. This suggests that the increased fetal adverse outcome in the early onset group was probably due to other causes other than the markedly elevated sFlt-1/PIGF ratio.

In conclusion, our study showed that comparing normotensive women with PE patients, there were increased sFlt-1 and decreased PIGF levels. While there was a strongly positive correlation between the mean arterial blood pressure and sFlt-1and sFlt-1/PIGF ratio, a negative correlation existed between the mean arterial blood pressure and PIGF. At the same time, sFlt-1/PIGF ratio may be of value in prediction of maternal and fetal outcome in PE patients.

\section{Limitation}

The study was performed in a single center and is of relatively small size. Although we were interested in all PE related adverse outcomes, we did not find some adverse events, such as pulmonary edema, disseminated intravascular coagulation and retinopathy in this study.

\section{Conflicts of Interest}

The authors declare no conflicts of interest regarding the publication of this paper.

\section{References}

[1] Lee-Ann Hawkins, T., Brown, M.A., Mangos, G.J. and Davis, G.K. (2012) Transient Gestational Hypertension: Not Always a Benign Event. Pregnancy Hypertension, 2, 22-27. https://doi.org/10.1016/j.preghy.2011.09.001

[2] Nouwen, E., Snijder, M., van Montfrans, G. and Wolf, H. (2012) Validation of the Omron M7 and Microlife 3BTO-A Blood Pressure Measuring Devices in Preeclampsia. Hypertension in Pregnancy, 31, 131-139. https://doi.org/10.3109/10641955.2010.544799

[3] Lindheimer, M.D. and Kanter, D. (2010) Interpreting Abnormal Proteinuria in Pregnancy: The Need for a More Pathophysiological Approach. Obstetrics \& Gynecology, 115, 365-375. https://doi.org/10.1097/AOG.0b013e3181cb9644

[4] Pratt, A., Da Silva Costa, F., Borg, A.J., Kalionis, B., Keogh, R., Murthi, P., et al. (2015) Placental-Derived Angiogenic Proteins and Their Contribution to the Pathogenesis of Preeclampsia. Angiogenesis, 18, 115-123. https://doi.org/10.1007/s10456-014-9452-3

[5] Helmo, F.R., Lopes, A.M., Carniero, C.D., Campos, C.G., Silva, P.B., et al. (2018) Angiogenic and Antiangiogenic Factors in Preeclampsia. Pathology-Research and Practice, 214, 7-14. https://doi.org/10.1016/j.prp.2017.10.021

[6] Basuni, M., Fathy, W.M. and Gaber, W. (2012) Assessment of Placental Growth Fac- 
tor and Soluble Vascular Endothelial Growth Factor Receptor 1 in the Prediction of Pre-Eclampsia. Egypt Journal of Haematology, 37, 281-286.

[7] Savvidou, M.D., Noori, M., Anderson, J.M., Hingorani, A.D. and Nicolaides, K.H. (2008) Maternal Endothelial Function and Serum Concentrations of Placental Growth Factor and Soluble Endoglin in Women with Abnormal Placentation. Ultrasound in Obstetrics \& Gynecology, 32, 871-876. https://doi.org/10.1002/uog.6126

[8] Stepan, H., Unversucht, A., Wessel, N. and Faber, R. (2007) Predictive Value of Maternal Angiogenic Factors in Second Trimester Pregnancies with Abnormal Uterine Perfusion. Hypertension, 49, 818-824. https://doi.org/10.1161/01.HYP.0000258404.21552.a3

[9] Levine, R.J., Maynard, S.E., Qian, C., Lim, K.H., England, L.J., et al. (2004) Circulating Angiogenic Factors and the Risk of Pre-Eclampsia. New England Journal of Medicine, 350, 672-683. https://doi.org/10.1056/NEJMoa031884

[10] Hertig, A., Berkane, N., Lefevre, G., Toumi, K., Marti, H.P., et al. (2004) Maternal Serum sFlt1 Concentration Is an Early and Reliable Predictive Marker of Pre-Eclampsia. Clinical Chemistry, 50, 1702-1703. https://doi.org/10.1373/clinchem.2004.036715

[11] Zhang, J., Klebanoff, M.A. and Roberts, J.M. (2001) Prediction of Adverse Outcomes by Common Definitions of Hypertension in Pregnancy. Obstetrics \& Gynecology, 97, 261-267. https://doi.org/10.1097/00006250-200102000-00018

[12] Verlohren, S., Herraiz, I., Lapaire, O., Schlembach, D., Moertl, M., et al. (2012) The sFlt-1/PlGF Ratio in Different Types of Hypertensive Pregnancy Disorders and Its Prognostic Potential in Preeclamptic Patients. American Journal of Obstetrics \& Gynecology, 206, 58.e1-58.e8. https://doi.org/10.1016/j.ajog.2011.07.037

[13] Gélinas, D.S., Bernatchez, P.N., Rollin, S., Bazan, N.G. and Sirois, M.G. (2002) Immediate and Delayed VEGF-Mediated NO Synthesis in Endothelial Cells: Role of PI3K, PKC 53 and PLC Pathways. British Journal of Pharmacology, 137, 1021-1030. https://doi.org/10.1038/sj.bjp.0704956

[14] Chaiworapongsa, T., Romero, R., Savasan, Z.A., Kusanovic, J.P., Ogge, G., et al. (2011) Maternal Plasma Concentrations of Angiogenic/Anti-Angiogenic Factors Are of Prognostic Value in Patients Presenting to the Obstetrical Triage Area with the Suspicion of Preeclampsia. The Journal of Maternal-Fetal \& Neonatal Medicine, 24, $1187-$ 1207. https://doi.org/10.3109/14767058.2011.589932

[15] Gómez-Arriaga, P.I., Herraiz, I., López-Jiménez, E.A., Escribano, D., Denk, B., et al. (2014) Uterine Artery Doppler and sFlt-1/PlGF Ratio: Prognostic Value in EarlyOnset Pre-Eclampsia. Ultrasound in Obstetrics \& Gynecology, 43, 525-532. https://doi.org/10.1002/uog.13224

[16] Espinoza, J., Romero, R., Nien, J.K., Gomez, R., Kusanovic, J.P., et al. (2007) Identification of Patients at Risk for Early Onset and/or Severe Pre-Eclampsia with the Use of Uterine Artery Doppler Velocimetry and Placental Growth Factor. American Journal of Obstetrics \& Gynecology, 196, 326.e1-326.e13. https://doi.org/10.1016/j.ajog.2006.11.002

[17] Glenn, I.D. (1992) Determining Sample Size. Fact Sheet PEOD-6, Florida Cooperative Extension Services, Institue of Food and Agricultural Sciences, University of Florida, Gainesville.

[18] Verlohren, S., Galindo, A., Schlembach, D., Zeisler, H., Herraiz, I., Moertl, M.G., et al. (2010) An Automated Method for the Determination of the sFlt-1/PIGF Ratio in the Assessment of Preeclampsia. American Journal of Obstetrics \& Gynecolog, 202, 161.e1-161.e11. https://doi.org/10.1016/j.ajog.2009.09.016 
[19] Teixeira, P.G., Reis, Z.S., Andrade, S.P., Rezende, C.A., Lage, E.M., et al. (2013) Presymptomatic Prediction of Pre-Eclampsia with Angiogenic Factors, in High Risk Pregnant Women. Hypertension in Pregnancy, 32, 312-320. https://doi.org/10.3109/10641955.2013.807818

[20] Nikuei, P., Rajaei, M., Roozbeh, N., Mohseni, F., Poordarvishi, F., Azad, M. and Haidari, S. (2020) Diagnostic Accuracy of sFlt-1/PIGF Ratio as a Marker of Preeclampsia. BMC Pregnancy and Childbirth, 20, Article No. 80. https://doi.org/10.1186/s12884-020-2744-2

[21] He, A., Zhou, Y., Wei, Y. and Li, R. (2020) Potential Protein Biomarkers for Preeclampsia. Cureus, 12, Article No. e8925. https://doi.org/10.7759/cureus.8925

[22] Brown, M.A., Lindheimer, M.D., De Swiet, M., Van Assche, A. and Moutquin, J.M. (2001) The Classification, Diagnosis and Management of the Hypertensive Disorders of Pregnancy: Statement from the International Society for the Study of Hypertension 49 in Pregnancy (ISSHP). Hypertension in Pregnancy, 20, 9-14.

[23] Maynard, S.E., Min, J.Y., Merchan, J., Lim, K.H., Li, J., et al. (2003) Excess Placental Soluble FMS-Like Tyrosine Kinase 1 (sFlt1) May Contribute to Endothelial Dysfunction, Hypertension, and Proteinuria in Pre-Eclampsia. Journal of Clinical Investigation, 111, 649-658. https://doi.org/10.1172/JCI17189

[24] Pant, V., Yadav, B.K. and Sharma, J. (2019) Cross-Sectional Study to Assess the sFlt1: PIGF Ratio in Pregnant Women with and without Preeclampsia. BMC Pregnancy and Childbirth, 19, Article No. 266. https://doi.org/10.1186/s12884-019-2399-Z

[25] Izzedine, H., Massard, C., Spano, J.P., Goldwasser, F., Khayat, D. and Soria, J.C. (2010) VEGF Signalling Inhibition-Induced Proteinuria: Mechanisms, Significance and Management. European Journal of Cancer, 46, 439-448.

https://doi.org/10.1016/j.ejca.2009.11.001

[26] Petzold, K., Jank, A., Faber, R. and Stepan, H. (2011) Relation between Maternal Angiogenic Factors and Utero-Placental Resistance in Normal First- and SecondTrimester Pregnancies. Hypertension in Pregnancy, 30, 401-407. https://doi.org/10.3109/10641955.2010.506234

[27] Soto, E., Romero, R., Kusanovic, J.P., Ogge, G., Hussein, Y., et al. (2012) Late-Onset Pre-Eclampsia Is Associated with an Imbalance of Angiogenic and Anti-Angiogenic Factors in Patients with and without Placental Lesions Consistent with Maternal Underperfusion. The Journal of Maternal-Fetal \& Neonatal Medicine, 25, 498-507. https://doi.org/10.3109/14767058.2011.591461

[28] Onyegbule, O.A., Meludu, S.C., Dioka, C.E., Udigwe, G.O., Udo, J.N., Ezidighoh, A.N., et al. (2014) Comparison of Serum Levels of Calcium and Magnesium among Preeclamptics and Normotensive Pregnant Women at Nnamdi Azikiwe University Teaching Hospital, Nnewi, Nigeria. International Journal of Research in Medical Sciences, 2, 404-408. https://doi.org/10.5455/2320-6012.ijrms20140506 